\title{
Does "Globalization" Make Agreement on International Public Policy Easier or Harder?
}

\author{
MSc. Erisa Xhixho \\ Faculty of Law, Tirana University \\ xhixhoerisa@gmail com
}

\author{
Doi:10.5901/ajis.2015.v4n1p167
}

\begin{abstract}
This research is a study about globalization which is nowadays one of the most debating issue in International Relations. Because of globalization today, countries, people, societies, cultures, commercial entities, etc., are closer to each other than ever, causing unimaginable chaos in this "traffic" that move people, money, goods, ideas, behavior patterns, etc. Therefore in this research will focus more on how globalization influences in international agreements making it difficult to achieve their signature for some reason. Today through globalization we have a different picture in the way of governance, which already have some actors that influence global decision-making and therefore often have difficulty in achieving consensus, because every one of them protects his interest or association that represents. Mainly between developed and democratic countries it is easy to reach agreement on protection the global values, but at the moment when they are violated may bring serious consequences on the political and diplomatic relations. Meanwhile in undemocratic states is difficult to achieve agreement.
\end{abstract}

Keywords: globalization, international public policy, law, human rights, implementation

\section{Introduction}

Globalization is perhaps the most serious discussion can take place today in social areas. All researchers, as well as all people, realize that the world today has become very " interdependent " (as it is called "social village"), as a result of the development of communication and movement, in a move made possible by the development of unimaginable technological. Today, countries, people, societies, cultures, commercial entities, etc., are closer to each other than ever, causing unimaginable chaos in this "traffic" that move people, money, goods, ideas, behavior patterns, etc. Therefore in this essay will focus more on how globalization influences in international agreements making it difficult to achieve their signature for some reason. Today through globalization we have a different picture in the way of governance, which already have some actors that influence global decision-making and therefore often have difficulty in achieving consensus, because every one of them protects his interest or association that represents. The inequality of states in global influence as a result of economic indicators, human resources, etc. has the consequence that, benefits from the agreements do not be the same for all countries, and becomes difficult to reach agreements on various issues, making the unification of the states in agreement, depend on the issue under consideration. While several mechanisms have been created with the goal to help achieve agreements between states, but they are not decisive, since decision-making again in most cases will be affected by the issue, and many other factors. Signature of the agreement is the first step of a long process that will continue with its implementation. It should be noted that global governance is a horizontal rather than hierarchical governance, leading to lack of institutions that would ensure implementation of agreements, followed by the lack of appropriate sanctions for countries that violate the agreement.

The only consequence that comes from non-implementation of the agreement is the risk of tension in diplomatic and political relations between states. Therefore the whole process of implementation becomes an obstacle for reaching agreement, as the sign states should consider whether you can implement or not, and all the consequences that can come from it. Undoubtedly, globalization being born as a result of awareness of states to protect certain values such as human rights, free market etc., has led to these agreements often dictate and global agenda. They often have become a source of irritation to the diplomatic and political relations between democratic states that have drafted and signed these agreements, as they stand at the heart of globalization.

So we can say that, necessarily mainly between developed and democratic countries it is easy to reach agreement on protection of these global values, but at the moment when they are violated may bring serious consequences on the political and diplomatic relations. Meanwhile in undemocratic states is difficult to achieve agreement.

The main objective of this paper is to show the importance of reaching international agreements between countries 
in the international arena, in view of their growth and development in the context of globalization.

For the realization of this paper is using analytical and comparative methodology. Analysis of the basic concepts :stakeholders,inequality,mechanisms, implementation and values of international agreements are placed at the center of this work, having aimed to identify the most important problems and improving the legal framework of existing practices, in order to develop more deeply the concept of globalization .

In fulfillment of this purpose, as comparative basis are held essential and general principles of international public policy.

\section{Actors}

As a result of globalization today we have a world with a different picture in her direction and exactly in the global decision-making will not see an actor but a few. Undoubtedly, the main actor is the state, states that permit their global alliance, but here will notice that the power of states is not the same when talking about the influence they have in the moment of decision making. On the other hand non-governmental organizations NGOs, intergovernmental organizations today are considered potential actors, who through training, awareness campaigns in favor of a decision not to exercise their influence. Experts, technicians, human capacities otherwise referred to as "the brain of humanity or the states", more and more are taking a decisive role in decision-making. They have transformed their knowledge of the necessary resources, that influence leadership at the time of making decisions in different areas ${ }^{1}$.

So given that globalization has led to the involvement of many actors that directly or indirectly affect global decision-making, obviously it brings that relationship to be more complex. This is because the global decision-making in most cases related to important issues affecting the interests of many states and other actors, such as human rights, peace keeping, welfare, economic issues, global warming, etc. Therefore, dialogue and cooperation are essential for the achievement of these agreements. In this regard, since they have many actors in the game, absolutely dialogue and cooperation is complicated and difficult. All in all countries bear some common values, since they have decided to create and engage in the global decision-making, through drafting and reaching these agreements, but on the other hand are the personal interests of individual states or groups of states, and sometimes interest groups that dominate in most cases, making more difficult the achievement of global decision making. As with many actors involved in decision-making, the more interest necessarily be synchronized and the more difficult it is to achieve global consensus or agreement.

\section{Inequality}

Inequality between countries is a characteristic of the global world and talk about inequality when I am talking about countries that have different power in the global world. Today we have poor countries and rich countries, even though they signed the same agreement on free trade, on the free movement of goods and people, for human rights, etc. This is the great debate that raises the third world today, identifying the benefits of the agreements are not the same for all member states, as they are created by powerful states to be privileged and to be enriched².

A typical case of global crisis years is precisely the agreement to establish a common Euro currency and unifying the financial system in a global system. Specifically Lloyd Gruber (chap 5) says that "states architect of the European Monetary System were intent that this agreement to preserve their positions, and thus to gain privileges through its reach to more countries to establish economic dependence on them in the future. Here I note that Germany was the main architect of this agreement, which earn by providing greater benefits and on the other side Greece lost, which still suffers and is economically dependent on the state of the EU"3.

This is due to the fact that some countries have more natural resources, expertise, infrastructure, social, economic, political, human capacity to benefit from the agreements. Here done and divergence between strong states and weak, causing some states to be decision making and other decision taking, following the decisions. History has shown that there was always states that have dominated in different periods because of their economic power, military, etc., in some instances has been the U.S., the other in England, Germany and most recently China, which more and more is begins to

\footnotetext{
${ }^{1}$ Harman S. and Williams D., Governing the world: Cases in global governance. Routledge 2013. p.199-201

${ }^{2}$ Halliday F., "Global Governance: Prospects and Problems". (2000) p. 27; Harman S. and Williams D., Governing the world: Cases in global governance. Routledge 2013. p. 204-205

${ }^{3}$ Barnett M. and Duvall R., "Power in global governance", Cambridge 2004. P .17 
emerge as a powerful state. So, if they refer to powerful states, they simply have to reach agreements as are precisely those that govern this process from the initial structure to achieve the final document. But on the other hand, other countries find it difficult to sign international agreements such as can't respond standards and conditions required by powerful countries. So they feel threatened by the fact that can be imposed on the things that they can't afford (as by the resources, human capacity and financial conditions) at the moment, but also in the future. Euro zone itself has been more skepticism, suspicion by many countries to sign, for the fact of the benefits that would bring to the state signatory.

On the other hand, in reality we have and situations where small countries seeking to sign international agreements, becoming part of international organizations influence the decision even though it is not very important, for example participation in NATO and the EU, where almost all Balkan countries seek to be part of this international organization. This after the entry into these organizations will increase their status in the international arena and would have other benefits arising from such participation, in terms of democratic values and national security. So it is worth mentioning that inequality between countries and the impact it can have on achieving international agreements will always depend on the issue discussed.

\section{Mechanisms}

The decision to create this global world will undoubtedly be accompanied by mechanisms that will help ensure its functionality. There was a need for creating an international legislation, which will be able to create some standards setting, some codes for the functioning of global governance. Also there is a need for the establishment and codification of international norms in order to serve for solving many problems that arise in the international arena. Ideas and knowledge would be another mechanism, which is becoming very important when it comes to creating statistics, analysis of the facts on which the decision should be based, certain to be as better as and so to ensure the efficient and consensus. Global policy works based on priority issues, as a very important mechanism, which has undoubtedly brought that through focus on issues of importance for the time being made to better achieve the goals. These mechanisms being put into function of the intergovernmental, civil society, states, etc. organizations, can certainly help to have a real measurement of efficiency and success of global decision making ${ }^{4}$.

So these mechanisms have helped countries achieve great historic agreement as is security threats, human right, crises or emergencies etc. Where one of the agreements made history as it mentions Kamradt-Scott (chapter 8) "and where these mechanisms were key source for providing financial establishment strategy for global health, such as HIV I AIDS. Also in the case of agreement Millennium Development Goals"5.

But on the other hand, these mechanisms have failed to help enough that states fall into consensus on the need for urgent intervention in the issue of global warming, as many interests are involved, actress, which for the moment circumstances have made it impossible reaching this agreement. Therefore global decision-making depends on the question you always discussed by the actors involved, the state that dominates at the moment. So, in general, these mechanisms have been established and are intended to help countries to achieve international decision-making, but are not always decisive in reaching agreement.

\section{Implementation}

The success of the international agreement shall always be measured by the degree of its implementation. History has shown that global governance could create many international agreements and in many cases they are signed by a huge number of states, but the question arises to will to be implemented and respected in any case for not violating them. The case that would mark the biggest debate about the importance of international agreements, it would be Sept. 11, when the U.S. under the fight against terrorism, will intervene by invading Iraq, thus causing a violation of international law, international organizations and international conventions. This event will open a debate and raise suspicion of implementation in any situation from the state of international agreements and their ability to resist time. Also, if you analyze the current situation of my country, a developing country, with 22 years of New Democracy, which is located in the EU integration processes, which has seen an influx of international agreements signatures while on the other hand must be approximation of legislation, but in fact do not find their full implementation. For this reason it becomes a serious

${ }^{4}$ Harman S. and Williams D., Governing the world: Cases in global governance. Routledge 2013. p.202-203

${ }^{5}$ Harman S. and Williams D., Governing the world: Cases in global governance. Routledge 2013. p. 203 
problem in our journey towards the EU, becoming the main recommendation of EU periodic progress reports for Albania.

Consequently, we can say that one of the main problems is the lack of global governance institutions that would ensure implementation of agreements, as the lack of efficiency of state sanctions for breaches that agreement. It makes very fragile agreements and where primary for their success remains the willingness of states to implement them. Once in my perspective agreements or treaties lacking in terms of executive power and here might be a need for case-by-case assessment. But on the other hand, more and more found the fact that non-implementation of an agreement may lead to irritation, tension in international relations. Today states that decide to violate or not to implement an agreement, should consider diplomatic and political consequences that can bring. Therefore the implementation process makes it difficult to reach agreement, as currently states that sign would take into account whether or not you can implement, and all the consequences that can come from it. In this process influences political, economic, socio-cultural relations etc. Once at the time of signing, each country takes into account their interests and whether they comply with the agreement.

\section{Value}

Globalization and global governance came as a result of awareness states after the Cold War period and the necessity of uniting all about some values that would make a peaceful world. The international community, will join about some fundamental values: democracy, the rule of law, human rights, free markets etc. According to Austin Ranney's observation: "All functions, global governance decision-making directly influence our daily life like marriage, Education, distribution of wealth, art, sports etc. It brings you as much as global decision-making to be supported in these values, the better our lives will be ${ }^{6}$. Thanks to these values and principles that all countries unanimously assert and believe that bring agreements and conventions. Confidence among states remain key to reaching agreements, often because its absence has become an excuse for not signing agreements or what is worse, even though states have signed violate them. The latest case that sparked a huge debate that brought shock and international arena is the situation in Syria, (deposited Its instrument of Accession to the "Chemical Weapons Convention, CWC" on 14 September 2013). This situation led to harsh U.S. reaction of some other important states, who claimed that according to the information provided in the field, which resulted Syrian government had used chemical weapons against population. This fact prompted the U.S. to threaten Syria with military intervention in defense of the Syrian population. Then Russia through diplomatic intervention will solve the situation. So it can be seen that the values of globalization have become a priority in the global agenda since the foundation of any decision on the respect for human rights. Another example is the current case "Snowden", according to his reports have thought that U.S. spy including thousands of calls recently the Mrs. Angela Merkel phone, and also the leaders of Italy, France, Brazil, Spain etc. This event marked today the largest crisis of trust between the U.S. and Europe and where every day by European leadership sought clarification from the U.S. government. Their claims stay in the fact that it is a violation of the core of human rights, privacy, and that it is brought to severely threatened diplomatic and political relations between them?

So, the human rights are values, the most important principle in the global world and that their failure can lead to serious consequences, and even more difficult agreements and relations between democratic states. The result is that in most cases between democratic and developed countries is easy to reach agreement in the field of values, basic principles, but at the moment when they are violated may bring serious consequences on the relations between them. Meanwhile in non-democratic countries it is difficult to achieve agreement, but on the other hand the spirit of globalization are also imposed in these countries through the democratization of their societies and over time.

\section{Conclusion}

Globalization is certainly positive for humanity, as intended to establish some mechanisms for operation and solving problems among countries, yet global decision making would still time to be easier to access. In itself the creation of this global governance brings to many actors involved, many interests, many issues that need resolution. Meanwhile, many values that are the foundation of globalization itself must be protected and given this way to lead the national and international agenda. All these agreements would not have if the value will not be respected and will not be implemented.

${ }^{6}$ Lawrence S. Finkelstein, "What is Global Governance", 1995. p.370

7 Josh Voorhees, 24.10.2013, "Snowden's Latest: NSA Spied on 35 World Leaders" http://www.theguardian.com/world/2013/oct/24/ nsa-surveillance-world-leaders-calls 
On the other hand, the management of all these factors that are inherent to government, and make it difficult to reach agreements. For this reason today talking about dialogue for consensus, collaboration as key tools that could bring success the agreements and moving forward. I'm in favor of the all inclusiveness in this process that, despite the difficulties encountered, would ensure a greater efficiency of global governance.

\section{References}

Sophie Harman and David Williams, 2013 "Governing the World"

Fred Halliday - "Global Governance: Prospects and Problems". (2000)

Lawrence Finkelstein, "What is Global Governance" 1995.

Michael Barnett and Raymond Duvall - "Power in global governance"

Steven Yearley - "Environmental Issue and Compression of the Globe"

Josh Voorhees, 24.10.2013, "Snowden's Latest: NSA Spied on 35 World Leaders", http://www.theguardian.com/world/2013/oct/24/nsasurveillance-world-leaders-calls

Michael Barnett and Raymond Duvall - "Power in Global Governance", Lloyd Gruber. 
